TIMOTHY CONNOLLY

\title{
INTRODUCTION: CHINESE PHILOSOPHY QUA PHILOSOPHY
}

In his introduction to the first issue of the Journal of Chinese Philosophy, Professor Chung-ying Cheng noted that Chinese philosophy

contains a wealth of pristine insights and unexplored materials for reflection and speculation. These insights and materials cover a wide spectrum of fundamental problems on nature, life, society, government and human destiny. They also present a whole world of invaluable philosophical perspectives and profoundly revealing experiences of human wisdom....

Yet Professor Cheng also worried that the philosophical richness of these perspectives had been neglected by previous approaches to Chinese thought. He founded the Journal out of a desire to remedy this situation, dedicating it to "the study of Chinese philosophy qua philosophy."

In spite of the evident philosophical value of many Chinese texts, the idea of "Chinese philosophy qua philosophy" raises a host of questions that continue to be debated. Can we apply a term invented by the ancient Greeks, and only translated into Chinese in the late nineteenth century, to the teachings of the pre-Qin masters? Does reading pre-twentieth-century Chinese texts as philosophy capture the issues of importance to their authors? Do we need to alter the definition of philosophy in order to engage with these issues?

Wilfred Sellars famously defined philosophy as "the attempt to understand how things, in the broadest sense of the term, hang together, in the broadest sense of that term." The conception of philosophy as thinking about "the big picture," familiar to most of us in one version or another, has some appeal to those who pursue its study across cultural boundaries. The editors of the Oxford Handbook of World Philosophy quote Sellars's definition in the opening line of their introduction, and go on to claim that "Any impartial view that surveys the world's cultures finds this kind of reasoned inquiry into who we are, our experience, and the nature of reality widely

TIM CONNOLLY, Associate Professor, Philosophy and Religious Studies Department, East Stroudsburg University. Specialties: ancient Greek philosophy, classical Chinese philosophy. E-mail: tconnolly@po-box.esu.edu

Journal of Chinese Philosophy 40:3-4 (September-December 2013) 377-380

(C) 2014 Journal of Chinese Philosophy 
distributed." If it is true that people everywhere wonder about the world around them and their place within it, then this prominent Western conception of philosophy is sufficient for cross-cultural comparison.

One problem with Sellars's definition is that it is too broad to be helpful. Philosophers from different historical periods have disagreed on which "things" are the proper objects of philosophical investigation. When we compare the answers to this question given by Aristotle, Kant, and Wittgenstein, we get three different answers; even more so when we begin to incorporate views from non-Western traditions. Some contemporary philosophers think that philosophy can't tell us anything about "big questions" such as the nature of reality. If you want to learn about such things, they would advise you to ask a physicist or chemist. ${ }^{2}$ Additionally, some scholars have worried that in lumping Chinese philosophy under the generic heading of "reasoned inquiry into fundamental questions" we run the risk of leveling out significant differences between it and Western philosophy. A preestablished notion of philosophy can lead us to fixate on the features of Chinese texts that look familiar to us, while ignoring less familiar but perhaps equally significant features. ${ }^{3}$

A second approach is to take the "family resemblance" model of philosophy. In opposition to the Socratic view that a concept can be analyzed in terms of some essential element common to all the individuals to which it applies, Wittgenstein argued that a concept word instead covers an extremely complicated nexus of various similarities of different kinds. What we call "games" points to a remarkable multiplicity of overlapping subgroupings-competitive games, games of chance, board games, card games, and so on-rather than to some single shared characteristic. The same might be said for what we call "philosophy." A main justification for a family resemblance model of philosophy to Chinese texts is that it helps us avoid an asymmetrical application of the term. As Victoria Harrison writes, the family resemblance approach "opens the way for the practice of global philosophy by allowing us to recognize different traditions as philosophical without requiring us to give any one of them a preeminent position as the paradigm case against which to judge all others." ${ }^{4}$

A typical reproach to the notion of family resemblances is that it leaves the application of a concept too unrestricted, since there is no mechanism for determining which family resemblances are essential and which are accidental. The same might be said for its cross-cultural version: how do we know which resemblances are meaningful, and ought to be explored further? This question and others will need to be carefully worked out. On the other hand, comparative philosophers find the idea of family resemblances useful because it allows them to 
retain some of the distinctive features of the Western philosophical tradition while still being open to the challenges other cultures may provide to the philosophical enterprise.

A third possibility is that we will not know the meaning and value of "Chinese philosophy qua philosophy" until we attempt to interpret it as such. I believe that Professor Cheng's own approach to Chinese philosophy falls under this general category. His methodology of analytic reconstruction comprises three activities:

1. Analyzing various basic views in Chinese philosophy in an attempt to display and reveal the intricate implications and relationships of concepts involved in these views

2. Making explicit the presuppositions and consequences of these views

3. Giving a systematic and critical explanation of the concepts and views under analysis ${ }^{5}$

According to Cheng, it is only through philosophically rigorous reconstruction that "the relevance of Chinese philosophy to modern philosophers and modern man will become manifest, and a comparison of Chinese philosophy with Western philosophy possible." ${ }^{\prime 6}$ His extensive body of research over the past five decades has applied this approach to an astounding variety of Chinese texts and philosophical topics.

Despite continuing debate about methodology, there is little doubt that interest in "Chinese philosophy qua philosophy" has continued to grow since the Journal's inception. An article published this year in the Chronicle of Higher Education called attention to the changes that have taken place since Professor Cheng's early efforts in the 1960s and early 1970s. ${ }^{7}$ We now see a significant number of sessions devoted to Chinese thought at the meetings of the American Philosophical Association, with some of them starting to appear on the main program of the Eastern Division. More than 100 scholars from all over the world attended this year's meeting of the International Society for Chinese Philosophy, the organization founded by Professor Cheng, in Buffalo, New York. Other organizations devoted to Chinese thought have sprung up, along with newer journals such as Dao: A Journal of Comparative Philosophy and Comparative Philosophy. As interest spreads, Chinese philosophy continues to challenge and enrich our conceptions of what the discipline of philosophy can offer.

Continued growth will mean attracting new generations of philosophers to the study of Chinese thinkers and texts. On a personal note, I would like to acknowledge the support for younger scholars that the Journal has offered in the past and continues to offer. After I had my 
first article accepted for publication at the Journal, the editors went out of their way to schedule a meeting with me at the upcoming APA, at which they took a sincere interest in my life and work. Since then they have offered me a great deal in the way of support and opportunities. I know of few other journals that can boast of the international and intergenerational web of relationships that the Journal has built in the last four decades, and I am grateful to the editors for allowing me to play a part in this.

For our anniversary volume, I would like to acknowledge the help and hard work of Professor Chung-ying Cheng and Dr. Linyu Gu, and also thank the following editorial members for their assistance: Professor Xinzhong Yao, Professor Mathew Foust, Dr. Shirley Chan, Professor Sebastian Billioud, Professor Karyn Lai, and others.

EAST STROUDSBURG East Stroudsburg, Pennsylvania

\section{ENDNOTES}

1. The Oxford Handbook of World Philosophy, eds. Jay L. Garfield and William Edelglass (New York: Oxford University Press, 2011), 3.

2. For this view, see Lao Sze-Kwang, "On Understanding Chinese Philosophy: An Inquiry and a Proposal," in Understanding the Chinese Mind: The Philosophical Roots, ed. Robert E. Allinson (New York: Oxford University Press), 266-7.

3. Carrine Defoort, for instance, writes that "Westerners who search for maxims and universal principles in ancient Chinese texts are like Chinese masters who would sift through the whole corpus of Western texts-from political manifestos to philosophical treatises - in search of prescriptions for coffins, without taking into account our current intellectual categories or philosophical interests.... A pernicious result of such intellectual mutilation is that the Chinese insights are exposed as primitive or naïve forms of familiar Western concepts, insights, and discussions that are themselves never called into question"; "Is There Such Thing as Chinese Philosophy? Arguments of an Implicit Debate," Philosophy East and West 51, no. 3 (2001): 393-413, at 401-2.

4. Victoria Harrison, Eastern Philosophy: The Basics (New York: Routledge, 2012), 5.

5. Chung-ying Cheng, New Dimensions of Confucian and Neo-Confucian Philosophy (Albany: State University of New York Press, 1991), 67 (with slight editing).

6. Ibid.

7. Carlin Romano, "Chinese Philosophy Lifts off in America," Chronicle of Higher Education, September 23, 2013 (http://chronicle.com/article/Dao-Rising-Chinese -Philosophy/141693/). 